\title{
Seminário como uma prática pedagógica a partir do sexto ano do Ensino Fundamental
}

Submetido - 23 out. 2021

Aprovado - 08 dez. 2021

Publicado - 15 dez. 2021

http://dx.doi.org/10.52755/sas.v.2i2.165

\begin{abstract}
Cristianni Antunes Leal (i)
Professora de Ciências e Biologia - Secretaria de Estado de Educação do Rio de Janeiro. Doutora em Ensino em Biociências e Saúde pela Fundação Oswaldo Cruz, FIOCRUZ, Brasil. E-mail: caleal1@gmail.com.
\end{abstract}

\section{RESUMO}

As escolas apresentam diversas estratégias de ensino e aprendizagem e uma delas é o seminário. Por isso, o foco temático deste estudo é apresentar o seminário como uma estratégia de ensino ativa que pode ser utilizada a partir do sexto ano do Ensino Fundamental. O objetivo foi refletir no seminário como estratégia didática formativa para os estudantes/indivíduos e para isso, o entendimento de teóricos acerca do uso do seminário, uns com defesas do seminário como desenvolvimento cognitivo, enquanto outros lhe veem como mais uma preparação para o mundo do trabalho. Seja como for, o debate de ideias é interessante para ver o quão plural é o uso dessa metodologia. Trata-se de um trabalho teórico, com um viés no relato de experiência em que minha experiência docente foi invocada na intercessão desta metodologia para o desenvolvimento de várias áreas cognitivas e sociais dos indivíduos. Desta forma, conclui-se que é essencial a utilização do seminário, com orientação e supervisão a partir do sexto ano.

Palavras-chave: Educação básica; Educação pública; Estratégia didática; Preposição como resultado.

\section{Seminar as a pedagogical practice from the sixth year of elementary school}

\begin{abstract}
Schools have different teaching and learning strategies and one of them is the seminar. Therefore, the thematic focus of this study is to present the seminar as an active teaching strategy that can be used from the sixth year of elementary school onwards. The objective was to reflect on the seminar as a didactic formative strategy for students/individuals and, for this, the understanding of theorists about the use of the seminar, some with defenses of the seminar as cognitive development, while others see it as another preparation for the world of work. In any case, the debate of ideas is interesting to see how plural the use of this methodology is. This is a theoretical work, with a bias in the report of experience where my teaching experience was invoked in the intercession of this methodology for the development of various cognitive and social areas of individuals. Thus, it is concluded that it is essential to use the seminar, with guidance and supervision from the sixth year onwards
\end{abstract}

Keywords: Basic education; Public education; Didactic strategy; Preposition as a result.

\section{Seminario como práctica pedagógica a partir del sexto año de primaria}

Este é um trabalho de acesso aberto e distribuído sob os Termos da Creative

Commons Attribution Attribution-NonCommercial-ShareAlike 4.0 International.

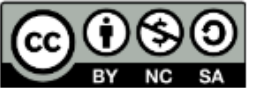




\section{RESUMEN}

Las escuelas tienen diferentes estrategias de enseñanza y aprendizaje y una de ellas es el seminario. Por lo tanto, el enfoque temático de este estudio es presentar el seminario como una estrategia de enseñanza activa que puede ser utilizada a partir del sexto año de la escuela primaria en adelante. El objetivo fue reflexionar sobre el seminario como una estrategia didáctica formativa para estudiantes / individuos y, para ello, la comprensión de los teóricos sobre el uso del seminario, algunos con las defensas del seminario como desarrollo cognitivo, mientras que otros lo ven como una preparación más. para el mundo del trabajo. En cualquier caso, el debate de ideas es interesante para ver cuán plural es el uso de esta metodología. Se trata de un trabajo teórico, con un sesgo en el relato de experiencia donde mi experiencia docente fue invocada en la intercesión de esta metodología para el desarrollo de diversas áreas cognitivas y sociales de los individuos. Así, se concluye que es fundamental la utilización del seminario, con orientación y supervisión a partir del sexto año en adelante.

Palabras clave: A Educación básica; Educacion publica; Estrategia didáctica; Preposición como resultado.

\section{Introdução}

De início, a proposta é assustadora para os indivíduos por nunca terem vivido tal experiência, por sempre terem sido passivos diante do processo de ensino e aprendizagem. Afinal, libertar-se da cadeira e assumir um papel ativo diante da turma e preferir-Ihes palavras e olhares, é uma novidade para escolares das turmas do sexto ano dos anos finais do Ensino Fundamental.

Para alguns estudantes pode ser algo menos incômodo por já ter vivido esta experiência em sua vida secular, como na igreja, por exemplo. Para outros, é extremamente desconfortante assumir um lugar onde é visto por todos e assumir a oratória por alguns momentos e proferir ensinamentos de um determinado tema, além de estarem expostos a julgamentos alheios.

Seminário - é a metodologia de ensino que causa medo e desconforto no início da vida escolar, mas é uma prática pedagógica que pode ser utilizada como estratégia didática para o ensino e aprendizagem de vários conteúdos, além de contribuir para o desenvolvimento cognitivo e social do indivíduo/cidadão para além da vida escolar.

O seminário é um gênero oral público que pertence à família dos gêneros expositivos, como o texto de divulgação científica e o texto didático. É uma apresentação para um grupo de pessoas, podendo ser de estudantes e professor, e talvez uma banca de avaliadores ou outros ouvintes. É bem 
comum no lócus escolar nos anos mais avançados, como também na academia (faculdade) e profissional. Logo, vê-se que o seminário tem importante papel na formação do indivíduo que frequenta hoje a escola e que pode iniciar a vivência da estratégia nesse ambiente.

A função do seminário é transmitir conhecimentos específicos (técnicos ou científicos) a respeito de um assunto relacionado à determinada área do conhecimento. Pode ser realizado individualmente ou em grupo, não requer grande infraestrutura, é de baixo custo, podendo ainda utilizar apoio de materiais expositivos, como um cartaz por exemplo, ou não. Logo, é uma técnica de ensino e aprendizagem que o professor pode utilizar em sua prática docente, desde que haja devidas preparações.

Leal, Miranda e Nova (2018) argumentam que tais preparações não precisam reprisar o que o docente viveu em seu momento enquanto estudante, haja vista que há novas tecnologias que podem cooperar com os estudantes. Não precisa ser um seminário tradicional com a reverberação de algo decorado como uma aula tradicional, onde o estudante memoriza o que estudou e declara mecanicamente à turma. Para os autores, o seminário é uma técnica de ensino e como tal, apresenta suas especificidades que podem ser modificadas diante dos estudantes encontrados em sala, considerando a infraestrutura e o contexto da escola e da turma como a maior maturidade para debater ideias contrárias ao apresentado, mas sem interpretar os debates de ideias como algo pessoal.

Tardif e Lessard (2014) sustentam em seus princípios que é na escola, nesse espaço, que os indivíduos expandem seus convívios sociais com privilégios, regras e obrigações, assim como o mundo do trabalho goza. Os autores canadenses veem a escola como um ambiente preparatório para o mundo do trabalho, onde formam trabalhadores. Com esse contexto, o seminário torna-se uma importante ferramenta comunicativa por ajudar a desenvolver nos indivíduos competências que serão requeridas quando eles forem trabalhadores, como a exposição oral, o pensamento, o respeito e o debate de ideias. 
O seminário pode ser usado na escola tradicional, embora ser considerado tradicional soa como uma ofensa; como afirmam Araújo e Praxedes (2013) a escola tradicional é centrada na figura do professor e em ser intelectualista e enciclopedista por querer passar tantos conteúdos aos estudantes, os autores ainda citam:

Outra característica típica dessa escola é o fato dela não considerar as particularidades de cada indivíduo, partindo do princípio que todos possuem - mesmo patamar de cognição, ou seja, considera a sala de aula homogênea, recomendando, inclusive, um maior empenho nas tarefas a serem realizadas para aqueles que encontrarem dificuldades (ARAÚJO; PRAXEDES, 2013, p. 245).

Como a memorização dos conteúdos repassados pelo professor e a postura passiva do estudante. Sabe-se que nenhuma turma é homogênea, ainda mais a de um sexto ano e que atualmente a escola tradicional in natura está desacreditada diante de tantas teorias e pesquisas no campo da educação, psicologia, sociologia, entre outras áreas que contribuem para afirmar que os estudantes são seres singulares e que aprendem de forma também singular, por isso, ser interessante diversificar as estratégias de ensino e aprendizagem para os hoje estudantes, mas amanhã trabalhadores.

Deste modo, o seminário é um preparo para o mundo do trabalho porque desenvolve competências e habilidades, como: a comunicação, o planejamento, o trabalho em equipe, a organização, de fundamentação de ideias, de produção do conhecimento individual e em equipe, a pesquisa, a proatividade, a leitura, encorajam o estudo individual e coletivo, além da criatividade, da autoavaliação, da argumentação crítica, da responsabilidade e da empatia, assim como a oralidade, a autonomia de pensamento e ação, a capacidade de integrar novos e antigos elementos já estudados ou vividos, ou seja, desenvolve nos (hoje) estudantes uma rotina de estudos e reflexão.

Esta metodologia ativa de aprendizagem pode ocorrer em qualquer nível de educação formal, ou seja, desde os primeiros anos do Ensino Fundamental em diante. Cabe ao docente dosar, orientar e acompanhar cada etapa e ano de escolaridade. Assim, trazendo novamente Tardif; Lessard, os pesquisadores dizem que: 
O ensino é visto como uma ocupação secundária ou periférica em relação ao trabalho material e produtivo. A docência e seus agentes ficam nisso subordinados à esfera da produção, porque sua missão primeira é preparar os filhos dos trabalhadores para o mercado de trabalho (TARDIF; LESSARD, 2014, p. 14 - grifo da autora).

A escola é um ambiente que prepara os indivíduos para o mercado de trabalho, uns com mais privilégios que outros, mas todos precisam cumprir a etapa da escolarização, que no Brasil é obrigatória e, portanto, gratuita. E ainda essencialmente frequente no ambiente coletivo que é a escola, o colégio. Cainelli (2011) aponta que na escola os professores do sexto ano em diante são menos afetivos que os das etapas anteriores, o que requer mais um movimento de mudanças para o estudante.

Mora (2017) vem com um discurso mais atenuante do ambiente escolar, para este pesquisador espanhol a idade em que os indivíduos frequentam a escola (da infância à adolescência) é um momento crucial para o desenvolvimento do cérebro por vivenciar experiências e fortalecer seus desejos por novas aprendizagens. O cérebro é capaz de ser modificado para melhor, mas conforme a pessoa vai envelhecendo, a plasticidade do cérebro diminui. Assim, está na faixa etária escolar (4/5/6 anos aos 17/18 anos ou mais - o autor não dá uma idade específica) um conveniente momento para explorar o cérebro com novas experiências e desafios, como o seminário é. Quanto mais estímulos, mais o cérebro dos estudantes/indivíduos vai se desenvolvendo.

Em vista disso, salienta-se que serão apresentados aqui frutos de anos de experiência valendo-se desta prática pedagógica a partir do sexto ano dos anos finais do Ensino Fundamental na disciplina Ciências e com a fundamentação teórica acerca da importância do seminário como estratégia de ensino. Assim sendo, este estudo tem como objetivo refletir no seminário como prática pedagógica formativa para os jovens estudantes/indivíduos.

Este estudo foi dividido em cinco seções, sendo elas o referencial teórico que assegura o seminário como uma prática de ensino de aprendizagem e sua importância em ser desenvolvido no contexto escolar para o indivíduo; seguido das especificidades das turmas do sexto ano. A terceira seção são recomendações para planejar seminários a partir do sexto 
ano. A quarta seção é uma tentativa de coser o objetivo, com o referencial mais a preposição deste estudo, que são as recomendações para realizar um seminário. A última seção são os comentários finais com a apreciação e inferência da autora. Trata-se de um texto encorajador para que outros colegas docentes venham também aderir a esta metodologia ativa de aprendizagem, também nomeada de estratégias didáticas, e verificarem o quão é válida no desenvolvimento dos estudantes, mesmo nos mais tenros, como os do sexto ano dos anos finais do Ensino Fundamental.

\section{Referencial teórico}

Esta seção tem como finalidade apresentar algumas linhas de raciocínio que mostram o uso do seminário como estratégia de ensino e aprendizagem na escola, para que os estudantes/indivíduos se desenvolvam nas capacitações que os seminários podem proporcionar-Ihes, além de mostrar o papel da escola na formação de trabalhadores. Assim, seguem as apresentações:

"[...] Seminário. Etimologicamente, o nome dessa técnica, Seminário, vem da palavra latina seminarium que significa viveiro de plantas onde se fazem as sementeiras. Sementeira indica a ideia de proliferação daquilo que se semeia" (LEAL; MIRANDA; NOVA, 2018, p. 70). Sendo o seminário uma forma de fomentar novas ideias e conhecimentos. Para tais autores, seminário significa a comunicação oral de algum tema de cunho acadêmico, cultural, científico ou tecnológico para um público específico. É um grupo de estudos com a apresentação do tema específico e posterior discussão e debates, mas com a presença e direção do professor responsável pela disciplina.

Para Leal, Miranda e Nova (2018), o seminário se mostra plural ao permitir trabalhar com várias faces do aprendizado e da criatividade do indivíduo e/ou grupo. É composto pela pesquisa e pela coleta de informações de dados. Ambos precisam ser confirmados para que o grupo não passe ou relate inverdades em seu seminário, haja visto que com o advento da internet na sala de aula por meio dos smartphones, o conhecimento pode ser contestado a qualquer momento, o que gera 
desconforto em quem apresenta, e desconfiança em quem ouve e participa. Os dados apresentados precisam ser verídicos e não do senso comum.

Os professores precisam apresentar e ensinar o que é um 'seminário' para os estudantes, portanto, o docente pode resgatar seu histórico enquanto estudante (possivelmente fruto de um ensino tradicional) ou ir buscar novas fontes de como fazer e apresentar um seminário, por isso o entendimento de classe social defendido por Tardif e Lessard (2014) e Bourdieu e Passeron (2014) é importante. Não é necessário que os estudantes fiquem perfilados na parede da sala de forma monótona, podem se movimentar, encenar, fazer degustações, júri simulado, serem criativos na forma de apresentar, abordar e discutir o tema que foi proposto, ou seja, os estudantes vão assumir uma atividade em que eles serão os protagonistas.

Ao professor cabe a função de orientar e, após a apresentação supervisionar os debates e participar, caso os estudantes precisem de ajuda. É um momento cooperativo, porque "o seminário é uma técnica de ensino socializado, na qual os alunos se reúnem em grupo com o objetivo de estudar e investigar um ou mais temas, sob a direção do professor" (LEAL; MIRANDA; NOVA, 2018, p. 74). A avaliação formativa também faz parte do processo do seminário.

Mora (2017) sustenta a ideia de que quanto mais desafiantes forem as atividades escolares, maiores o desenvolvimento cognitivo dos indivíduos participantes, mas alerta para a presença constante dos professores na supervisão das atividades. Em relação a seminários, como esses se apresentam inicialmente com muitos desafios: apresentação oral, desenvolvimento de uma linha de raciocínio e de apresentação, postura corporal, na frente da turma, conhecimento de um tema, entre outros, o cérebro juvenil dos estudantes do sexto ano tem a capacidade de atender a este desafio. O que não pode se tornar é uma competição entre indivíduos e turmas, precisa ser algo prazeroso e empático, para que gere aprendizagem.

Os humanos seguem aprendendo a vida toda, é o que afirma a neuroeducação que é uma nova perspectiva de ensino baseada na 
neurociência. A neuroeducação tem a vantagem dos conhecimentos do cérebro integrados com a psicologia, sociologia e a medicina, com o intento de melhorar e potencializar tanto os processos de aprendizagem e memória dos estudantes como orientar melhor os professores em como ensinar. Mora (2017) defende que cada indivíduo tem um tempo diferente para o desenvolvimento, maturação e envelhecimento cerebral, e a educação pode ajudar aos indivíduos a aprender cedo e desenvolver suas habilidades cognitivas, para isto, basta orientar e dar-Ihes desafios, sem nunca estarem sozinhos em seus primeiros passos.

Emoções, sensações e impressões são básicas para os próprios processos cognitivos das pessoas, porque colaboram para o aprendizado, são elas (as positivas): a alegria, o amor, o companheirismo, a empatia, a curiosidade, a atenção (a atenção permite que o cérebro aprenda e memorize a informação que procede do mundo que rodeia os indivíduos), a resiliência, entre outras. Há diversas emoções, como também há as negativas, que causam sentimentos desagradáveis nos indivíduos, como o medo. Mas, todas elas e as que não foram citadas, cooperam para que se molde o indivíduo e que ele aprenda; aprenda na escola, na universidade, no trabalho, na sociedade, seja qual for o espaço social ocupado, todas estas emoções ensinam algo ao indivíduo. $\mathrm{E}$ a escola/colégio tem a possibilidade de desde cedo ensinar emoções para que os indivíduos aprendam os mais diversos saberes, pois suas redes neurais estão em expansão e quanto mais estímulos, mais os indivíduos aprenderão sozinhos e/ou em grupos sociais que frequentam (MORA, 2017).

Quanto mais estratégias de ensino forem oferecidas aos atores escolares, mais desafios os estudantes irão ter e aprender. Contudo, não há garantias que os indivíduos aprendam todos no mesmo tempo e do mesmo jeito, por isso ser importante a oferta de variadas estratégias de ensino, e o seminário é uma delas. Embora existam diversificadas metodologias de ensino e aprendizagem ativas, e elas recebam o nome de "estratégias didáticas", há sinônimos para este termo que se mostra polissêmico, seja qual for o termo usado, as estratégias têm em comum requerer um papel ativo e protagonista dos estudantes para o aprender (LEAL, 2017). Há 
diversas teorias cognitivas que assentam com tal afirmativa, aqui se apresenta brevemente a Autopoiese.

A teoria da Autopoiese foi elaborada por dois biólogos chilenos na década de 1960 (MATURANA; VARELA, 2011; MATURANA, 2014). De acordo com os autores, Autopoiese vem de poiesis, um termo grego que significa 'produção', logo, Autopoiese significa autoprodução. Na educação, cada indivíduo ao ser apresentado a um conteúdo e metodologia de ensino faz sua autoaprendizagem, considerando suas "emoções e amor" - o processo biossocial; pontos considerados por Humberto Maturana. O autor considera que o emocional não é uma limitação para a racionalidade, mas condição de possibilidade para aprender. Autopoiese considera que quando o indivíduo é ativo em seu processo educativo a aprendizagem pode acontecer, e senão no momento, em outras ocasiões futuras por terem acumulado experiências que podem beneficiar a aprendizagem.

A escolha da estratégia didática pelo professor para ser usada com os estudantes precisa levar em conta: a ativa participação dos estudantes, um elevado grau de realidade ou concretização dos estudantes e, um maior interesse pessoal ou envolvimento dos estudantes. E ainda os objetivos a serem atingidos com o uso da estratégia, ao considerar a metodologia do professor que julga e avalia o papel do estudante e dos recursos disponíveis. Neste ponto, o docente precisa conhecer as estratégias para fazer a escolha (VIEIRA; VIEIRA, 2005). O seminário já é um companheiro do professor, que provavelmente, o utilizou em sua formação docente, mas que precisa ser ensinado aos estudantes para depois ser usado como uma ferramenta instrutiva e avaliativa.

Vê-se que com os autores supracitados, o seminário é considerado uma estratégia de ensino/metodologia ativa (termos polissêmicos pelos autores) e que pode colaborar para o desenvolvimento cognitivo, pessoal e social dos indivíduos.

Portanto, os seminários, como interpretados aqui neste trabalho são vistos como uma estratégia/metodologia de ensino, tendo a propriedade e condições de desenvolver cognitivamente os indivíduos que frequentam a 
escola; mas há outros olhares acerca do papel da escola e de suas estratégias/metodologias de ensino, é uma linha mais sociológica, filosófica, antropológica e econômica. Há duas abordagens a seguir com Tardif e Lessard (2014); Bourdieu e Passeron (2014) que veem a escola como um local de formação de trabalhadores e controle de suas condutas, sendo o seminário um desses controles de conduta e de ideias.

Para os canadenses Tardif e Lessard (2014) os estudantes são atores escolares que desempenham um papel no espaço da escola e ao seu fim, espera-se um resultado: trabalhadores, que usufruam de serviços. $O$ trabalho docente tem como 'objeto de trabalho' os seres humanos, e tem como objetivo "ao que chamamos aqui de trabalho interativo, cuja característica essencial é colocar em relação, no quadro de uma organização (escola, hospitais, serviços sociais, prisões, etc.), um trabalhador e um ser humano que se utiliza de seus serviços" (TARDIF; LESSARD, 2014, p. 19).

Sobre esse viés que os autores veem a escola como treinamento para a vida de trabalhador, com regras, posturas. A escola hoje trata "uma grande massa de indivíduos de acordo com padrões uniformes por um longo período de tempo [16 anos de educação básica no Brasil, ao menos], para reproduzir resultados semelhantes" (TARDIF; LESSARD, 2014, p. 24), ela não se limita a apenas o ensino e aprendizagem de conteúdos socialmente e culturalmente construídos, mas de formas, atitudes, modos de trabalho e até mesmo opiniões e ideais. Na escola há diversos tipos de trabalhos que os professores podem ofertar aos estudantes, como: o trabalho cognitivo, o trabalho sobre o outro, o trabalho material, todos em prol de um resultado ao final dos anos escolares: formar mão de obra trabalhadora e que oferte e utilize serviços oferecidos para, e pela sociedade.

Para alcançar tais resultados a escola utiliza-se de rotinas: uniformes, regras, exercícios, passividade, sinal, mas ela também é ambígua, pois deseja ensinar sempre algo além do previsto, do currículo instituído, pois lida com seres humanos, que seria nomeado de 'capital cultural'. Esta mesma escola positivista e behaviorista, deseja estudantes socioconstrutivistas, ativos, críticos-reflexivos; para tanto, deve "educar e 
instruir, socializar e formar" (TARDIF; LESSARD, 2014, p. 198) e talvez subverter-se, pois "os programas escolares oficiais são lineares e cumulativos, enquanto ensinar é, em boa parte, repetir, retomar, redizer, rever, voltar atrás, dar voltas para chegar ao mesmo lugar..." (TARDIF; LESSARD, 2014, p. 218).

O trabalhador docente, com entendimento de classe social, deseja que seus estudantes (os indivíduos ou 'unidades autopoiéticas' para Maturana) ação de sua prática pedagógica, sejam críticos o suficiente para compreenderem as questões sociais e econômicas que rondam a escola, a sociedade. E como fazer isso a partir do sexto ano dos anos finais do Ensino Fundamental? Um start seja a pesquisa e apresentação da mesma por meio de seminários à turma, porque como afirmam os pesquisadores Tardif; Lessard (2014) "não existe uma maneira objetiva ou geral de ensinar, visto que cada professor dá à sua prática as cores das suas próprias relações com outras pessoas" (p. 271). Os professores com entendimento de classe, tentam subverter tal visão.

Já os franceses Bourdieu e Passeron (2014) foram uns dos pioneiros em afirmar que a escola é um espaço da reprodução social e um eficiente domínio de legitimação das desigualdades, uma vez que a escola é vista pelos autores como um local, uma instituição que reproduz a sociedade e seus valores e que efetiva e legaliza as desigualdades em todos os aspectos, pois é na escola que o legado econômico da família se transforma em capital cultural. Há uma dominação social e é na escola que se aprende - lugar de cada um na sociedade de prestadores de serviços e de usuários, por terem o capital e por fazerem o capital circular na sociedade.

Segundo Bourdieu e Passeron (2014), as avaliações impõem uma definição social do conhecimento e da maneira de manifestá-lo, ou seja, padroniza respostas e reações relacionadas a determinados conteúdos e limita de certa forma, o conhecimento e as capacidades adquiridas e desenvolvidas ao longo dos anos. Assim, a escola utiliza a avaliação para selecionar os indivíduos tecnicamente mais competentes e os classifica desde os primeiros anos de vida escolar, colocando-os sob o status de nobreza escolar. 
Essa avaliação a que os franceses consideram em seu livro é a avaliação tradicional e que estimula a competição, a 'prova'. Os autores fizeram sua obra refletindo nos modelos da escola Frances da década de 1970, mas podem-se fazer alusões ao sistema brasileiro de educação, ainda muito preso nas avaliações somativas e classificatórias, ao invés das formativas e diagnósticas para uma intervenção positiva. Bourdieu e Passeron (2014) despedem-se de sua obra sem grandes esperanças para os indivíduos, apenas o conhecimento e a socialização do mesmo para 'mudar' a reprodução de uma escola classificatória, 'neutra', higienista, preparatória, acrítica, machista, hegemônica e heteronormativa.

À vista disso, a busca por um referencial teórico que abordasse a apresentação de seminários pelos estudantes da educação básica em artigos foi ínfima, a maioria relacionada com o curso de Letras e desenvolvimento oral dos indivíduos, demonstrando então uma carência nesta abordagem: a apresentação de seminário por escolares da educação básica.

O trabalho de Roncato e Lacerda (2005) apresenta um olhar no desenvolvimento da fala dos estudantes da educação infantil, por serem fonoaudiólogas veem o seminário como uma importante metodologia de ensino ativa para estimular, junto com os professores regentes, a fala e oratória dos estudantes.

Aqui vê-se a importância do seminário desde as mais tenras idades, mas como não são professores, as autoras têm um olhar no como os estudantes falam e narram suas histórias, independe do conteúdo que está sendo lecionado, da linha de raciocínio seguida, este papel cabe aos professores. É um trabalho colaborativo entre professores e fonoaudiólogos nas falas dos estudantes. E eles falam por meio de seminários. Encontrando um desvio na oralidade, os estudantes são encaminhados para a fonoaudiologia. Portanto, é mais um passo importante em realizar seminários na educação básica: também colabora para a saúde dos estudantes ao se perceber uma dificuldade em suas falas. Percebendo a dificuldade na oralidade, a escola pode encaminhar os estudantes para a fonoaudiologia, ou demais profissionais. 
Enquanto Meira e Silva (2013) trazem como colaboração a afirmação do seminário como técnica de ensino, pois é um gênero textual, os autores afirmam que há um número restrito de trabalhos realizados sobre o seminário e que não há profundidade em uma conceituação teórica linear, apresentando o seminário como uma conversa e/ou técnica, ora como gênero, ora como evento comunicativo. Mas o foco é o seminário acadêmico, mostrando mais uma vez uma lacuna na discussão dos seminários na educação básica como metodologia ativa de ensino.

Os autores também resgatam a origem latina do seminário, para eles essa definição aponta para a noção de espaço de crescimento e construção, que alguém (seminaristas) propõe-se a disseminar um saber no campo fértil da sala de aula, ambiente propício para que ele cresça, sendo sempre regados por situações semelhantes de plantio de novos saberes (MEIRA; SILVA, 2013).

Assim, o seminário é um momento de desenvolvimento da competência comunicativa do sujeito, utilizando a língua a partir de experiências sociais. É um evento comunicativo inserido em uma prática pedagógica, mas que precisa ser ensinado e de planejamento, execução e avaliação. Permite o desenvolvimento cognitivo e social, além de competências e habilidades que podem no futuro serem usadas no mundo do trabalho, e um olhar mais atencioso nas turmas mais tenras, como no sexto ano dos anos finais do Ensino Fundamental faz-se necessário para o uso do seminário.

\section{Sexto ano dos anos finais do Ensino Fundamental... em diante}

Nesta seção, apresentam-se as questões que são frutos de experiências peculiares do sexto ano dos anos finais do Ensino Fundamental, vivenciadas na educação pública, por isso ser um relato de experiência. Isto ocorre porque até o quinto ano dos anos iniciais do Ensino Fundamental, normalmente a turma, o estudante, tem poucos professores, mas quando chega ao sexto ano, depara-se com oito disciplinas, sendo elas (de forma geral): Artes, Ciências, Educação Física, Geografia, História, 
Língua Estrangeira, Língua Portuguesa e Matemática. As disciplinas são ministradas por diferentes professores, cada professor com seu ritmo e gestão de classe e de matéria (TARDIF, 2014).

Os anos finais do Ensino Fundamental abarcam a educação para crianças, pré-adolescentes e adolescentes dos 11 aos 14/15 anos, e contempla do sexto ao nono ano. Período etário em que os jovens enfrentam grandes desafios, sendo um deles a autonomia do estudante no processo de ensino e aprendizagem, ou seja, o docente do sexto ano espera encontrar um estudante autônomo e proativo. Já o Ensino Médio compreende a última etapa da educação básica, em que há a adição de novas disciplinas, como a Filosofia e a Sociologia, e, geralmente o Ensino Médio é compreendido em três anos.

O mais marcante do sexto ano é a presença de uma diversidade de professores, denominados professores especialistas, pois tiveram uma formação específica, por exemplo: o de Matemática é formado em Matemática e o de Geografia é formado em Geografia. Não há nesta etapa a presença do Pedagogo ou do professor do curso Normal de Formação de Professores (os professores polivalentes), isso significa que se o estudante que for para o sexto ano não tiver sido alfabetizado adequadamente, dificilmente esta dificuldade será sanada nos anos finais do Ensino Fundamental em diante, sendo necessário que os tutores busquem um amparo ou que a escola, dentro de suas condições, encaminhe o estudante para o reforço escolar.

Infelizmente, na escola pública há vários casos de estudantes analfabetos que chegaram ao sexto ano, se não ocorrer uma labuta pessoal da equipe pedagógica da escola e juntamente com os tutores, este estudante ficará retido no sexto ano e cada ano acumulando a discrepância entre série e idade. Existe um momento para a alfabetização, e não é nos anos finais do Ensino Fundamental, é antes, já que os professores especialistas não têm a formação para a alfabetização e nem tempo para isto, por conta de seus componentes curriculares. 
A presença de vários professores causa, para alguns estudantes, confusão, amedrontamento, alguns mudam de escola, chegam a mudar de turma por não se adaptarem ao professor/aos professores. É uma etapa desafiante, onde o estudante terá que se organizar (gestão de tempo) e amadurecer para cumprir as regras da série, como uma formação para o mercado de trabalho (BOURDIEU; PASSERON, 2014; TARDIF; LESSARD, 2014). A presença da família e tutores é bem-vinda nesta transição para amparar o estudante e ajudá-lo a se organizar, cooperando com a escola.

O desejado nesta etapa é o desenvolvimento do estudante, tanto cognitivo, quanto social. Para alcançar tal objetivo, os professores, cada um a sua maneira, leciona sua disciplina, buscando letrar os estudantes nos temas propostos e assim alcançar a autonomia desejada. São etapas sequenciais até a terceira série do Ensino Médio (17/18 anos, quando ininterruptos). E são momentos em que o estudante perpassa por inúmeras transformações e experiências porque a educação básica é muito vivencial.

Outra peculiaridade do sexto ano é a demanda para administrar diversas matérias e com diversos professores. Cainelli (2011) apresenta em seu estudo, na educação pública, que chama a atenção para as abordagens que são realizadas de forma diferente dos anos iniciais, assim como as relações dos sujeitos: estudantes e professores, bem como ao binômio Estado/município. A autora problematiza a transição:

O que provoca a tal 'ruptura' no entendimento de escola que os estudantes tinham até então, pois por serem de sistemas diferentes, não há continuidade e nem articulação entre as esferas públicas, até as cargas horárias das disciplinas são diferentes do que viam, até então, nas escolas da Prefeitura, cuja ênfase é maior em Matemática e Língua Portuguesa. "O aluno que transita de um sistema para outro inicia praticamente do zero uma nova vida escolar [...] na nova realidade, encontra um sistema que desconfia de sua formação e realiza diagnósticos para saber seu nível de aprendizagem" (CAINELLI, 2011, p. 129). Os estudantes é que migram de um lugar (escolas municipais) para outro (escolas estaduais), o que gera um estresse no estudante pelo desconhecido. 
Já que o desconhecido amedronta, o ideal é que haja uma transição lenta e segura para o sexto ano e que os professores deste ano de escolaridade tenham uma maior atenção e afetividade para estes estudantes, assim como com suas metodologias de ensino e aprendizagem sejam adequadas a este nível escolar.

Os estudantes chegam amedrontados, chamando os professores de 'tio' e 'tia', impõem-se a eles uma autonomia (que muitos ainda não tem), requer uma proatividade, rotina de estudos e leitura, que muitos ainda não desenvolveram; além de terem colegas novos também na turma. Inicialmente, no ano letivo, o ideal é que sejam realizadas atividades que apresentem os professores, a escola, os espaços escolares, as formas de avaliações, a média das avaliações, o número do telefone da escola, coisas banais, mas para um estudante que migra de uma escola municipal e vai para uma escola/colégio estadual, são vias de suavizar o estresse e o medo deste estudante. Feito isso, após os quatro primeiros meses os estudantes já estão adaptados à escola, na maioria dos casos. Contudo, casos não previstos devem ser identificados e levados à orientação pedagógica.

As autoras Montezi e Souza (2013) indicam que no sexto ano iniciase a adolescência da maioria dos estudantes, e que é um momento de transição de emoções, sentimentos, sendo necessário orientação para um desenvolvimento salutar. A adolescência é considerada uma fase de rebeldia e transgressão, o que pode causar mal aos próprios adolescentes. Há também um crescente desinteresse dos adolescentes pelas práticas escolares, principalmente as relativas ao ensino de conteúdos. Em particular, o sexto ano é uma fase de miscelâneas, onde alguns estudantes já são adolescentes, outros são pré-adolescentes, enquanto ainda há a prevalência das crianças.

De fato e diante deste quadro, o sexto ano mostra-se uma "caixa de surpresa" e os professores desejando dar o conteúdo de suas disciplinas e ignorando estas transições e questões. Na escola pública há ainda mais o distúrbio série/idade em que os estudantes estão fora da série que deveriam estar, estão atrasados e as turmas são cheias, com média de trinta e cinco estudantes, cada um com a sua demanda pessoal. O professor especialista, 
distante deste panorama, ignora qualquer sinal de dificuldade de aprendizagem e de adaptação e fornece aos estudantes os conteúdos disciplinares (TARDIF, 2014).

Ante o exposto, compreende-se o quão plural seja uma turma de sexto ano em uma escola pública, mas diante desse imbróglio, o que fazer? Montezi e Souza (2013) sustentam a ideia de que práticas escolares criativas podem ser uma alternativa para abarcar a todos nas turmas, como o seminário é.

No sexto ano os estudantes podem chegar à escola um pouco mais tímidos, mas eles estarão na escola de segunda à sexta-feira, portanto, a questão de conhecer o espaço torna-se natural pela própria questão da curiosidade dos estudantes e a relação com os colegas da escola nova.

Ocorrendo metodologias ativas de aprendizagem logo no sexto ano, mas com amparo docente para que o estudante não tenha nenhum abalo que o traumatize nesse espaço formativo; nas séries seguintes, as práticas pedagógicas tornam-se 'naturalizadas', os estudantes já sabem o que fazer, como fazer, o que se esperam deles e vão desenvolvendo a criatividade e rompendo seus próprios limites. Quando chegarem ao Ensino Médio, disciplinas como Filosofia e Sociologia que requerem o debate de ideias não se tornam em desentendimentos, aborrecimentos ou questões pessoais, porque os estudantes viram e veem que ter diferentes visões sobre um mesmo tema é importante para sociedade e discussão de ideias.

Portanto, os estudantes em suas séries escolares vão se desenvolvendo conforme novos desafios vão sendo dados, e eles conseguem vencer, o que não deve ocorrer é o constrangimento, o bullying, o ciberbullying, as críticas sempre negativas do professor. Qualquer atividade escolar que gere no estudante insegurança, ansiedade, pânico, ojeriza, entre outros, precisa ser revista e o docente também precisa se autoavaliar. Práticas pedagógicas, como o seminário é para despertar, desenvolver, favorecer, aflorar, fortalecer novas aprendizagens. $O$ docente parabenizar cada etapa superada é importante nesta série e parabenizar a todos, sem exclusão. 
As estratégias didáticas têm como função ensinar determinado conteúdo, mas elas vão além, quando desenvolvem outras áreas do indivíduo como a oralidade (RONCATO; LACERDA, 2005), e elas podem ser prazerosas, porque a escola atual, mesmo com tantas novidades tecnológicas ainda reproduz o modelo fordista e presidiário (BOURDIEU; PASSERON, 2014), por conseguinte é 'chata' aos olhos adolescentes do sexto ano em diante. Mas a novidade do seminário se conduzido corretamente pelo docente, pode-se tornar uma técnica prazerosa e criativa.

Diante do exposto, percebe-se o que é trabalhar pedagogicamente com o sexto ano, mas com as devidas orientações, todos os estudantes são capazes de progredir ainda mais, isso porque a maioria não é tímida, eles chegam à escola com muita vontade de aprender, de perguntar, de participar da aula, eles aceitam todas as estratégias didáticas que o professor propor, mas ao longo dos anos escolares esse desejo pelo saber diminui, sendo as metodologias ativas de ensino uma alternativa para contornar tal apatia, pois têm características para sempre manter o desejo pelo conhecimento. Por isso que a seguir será exposto uma dessas metodologias, o seminário e as orientações para o desenvolvimento dos estudantes.

\section{Recomendações com relação a seminários: a preposição}

Nesta seção serão compartilhados os conselhos de uma professora que trabalha com o sexto ano a mais de dez anos na educação pública, é a preposição deste estudo, e que se utiliza do seminário como prática pedagógica para o ensino e a aprendizagem. Trata-se de uma seção mais descritiva do que dialogada com o referencial teórico, por trazer a experiência da sala de aula vivenciada, é um relato de experiência, com uma narrativa autobiográfica.

Por serem jovens, os estudantes precisam de um professor orientador para suas ações, pesquisas, temas, apresentações, instrumentos, maquetes, cartazes, entre outras dúvidas e assuntos, logo, assim que a proposta do seminário for dada e aceita, um canal de comunicação precisa ser criado, pois, a partir do momento que é a primeira vez deles, é normal 
surgirem dúvidas. Estar disposto a orientá-los além da sala de aula torna-se um quesito necessário do docente.

No sexto ano os estudantes necessitam ter um professor para orientá-los de forma mais incisiva, ou seja, qualquer questão que surja é necessária que os estudantes saibam a que professor requerer, significa que é importante haver um professor representante para cada turma e que a turma saiba quem é o professor a quem deve recorrer, se necessário. Assim, tendo questões a serem resolvidas, os estudantes vão ao encalço deste professor. O ideal é que seja um professor cuja disciplina apresenta mais horas durante a semana para que o trabalho pedagógico não seja prejudicado por tais demandas, que podem ser ou não, disciplinares.

Os professores que aderirem ao seminário, não precisam propor sozinhos em suas salas de aula, podem convidar outros colegas, assim, a disseminação desta prática pedagógica também ocorre por meio dos saberes docentes (TARDIF, 2014) e todos podem colaborar para a pesquisa, o desenvolvimento e a apresentação do seminário junto com os estudantes.

Retornando a reflexão para os seminários, em razão de o seminário ser um gênero que tem por objetivo a transmissão de conhecimentos, é fundamental que o apresentador esteja muito bem-preparado em relação ao assunto a ser abordado e posteriormente debatido com o professor/os professores e a turma.

"O seminário é uma técnica que deveria demandar ampliação e polinização de ideias. Não é e não pode ser aquela técnica de ensino em que cada aluno apresenta uma parte de um texto (capítulo), ou quando alguém fala: 'ah! Vamos pular essa parte porque fulano faltou'" (LEAL; MIRANDA; NOVA, 2018, p. 71). A apresentação de seminários pelos grupos não precisa ser uma memorização que será verbalizada sem interrupções e de forma robotizada.

Seminário também é avaliação e contribui para a autoavaliação dos participantes. Contudo, para que seja proveitoso para todos os participantes, o seminário deve ser construído com antecedência, ou seja, assim que o 
professor passou a estratégia didática, o estudante já deve iniciar o preparativo. Por isso, é necessário planejar e preparar o seminário, passando por várias etapas, descritas a seguir nas subseções:

\section{Pesquisa}

Pesquisa atualizada em livrarias, bibliotecas, na internet (Wikipédia não é recomendado por ser uma plataforma que pode ser editada por qualquer usuário), jornais, revistas especializadas, vídeos, sítios eletrônicos de instituições públicas, como das Universidades, entre outros. Poderão servir como fontes de informação sobre o tema. Lembrar de anotar a referência de onde pegou a informação, pois será necessária para o tópico Referência (antiga Bibliografia).

\section{Tomada de notas}

Necessário tomar notas, resumir ou reproduzir textos verbais e não verbais que possam ser úteis para a exposição. Esse trabalho deve ter em vista a produção de um roteiro para ser utilizado no momento da apresentação. Por isso, a anotação de tudo o que for útil para enriquecer o texto é importante, como: dados históricos ou estatísticos, citações, comparações, exemplos, entre outros. Seja crítico com a coleta e análise de informações.

\section{Seleção e organização de informações e recursos materiais}

Seleção e organização das informações, tendo em vista os seguintes aspectos da exposição:

- Como introduzir, desenvolver e concluir a exposição;

- Quais subtemas serão abordados no desenvolvimento;

- Quais exemplos ou apoios (gráficos, dados estatísticos, maquetes) serão utilizados para fundamentar a exposição;

- Integração de outras disciplinas, ou seja, o conhecimento interdisciplinar pode ser requerido; 
- Que materiais e recursos audiovisuais (cartazes, apostilas, quadro, datashow, microfone, maquete, entre outros) serão necessários.

Nesse planejamento, devem ser levadas em conta as características do público-alvo que irá participar do seminário, como faixa etária, tipos de interesse, expectativas e conhecimentos prévios em relação ao tema abordado. Para dar à exposição um encaminhamento agradável, é importante intercalar o uso da voz com o uso de recursos audiovisuais, como maquetes e cartazes.

\section{Produção de roteiro e esquema}

Primeiramente, redigir um roteiro que permita visualizar não apenas o conjunto das informações que serão apresentadas, mas também a sequência em que isso vai ocorrer. Esse roteiro deve conter: informaçõeschave que orientarão o pensamento durante a exposição; indicação de recursos audiovisuais (se for o caso); textos de autoridades ou especialistas que serão citados. Posteriormente, pode-se redigir um esquema, isto é, um conjunto de anotações breves que servirão como apoio durante a exposição. Se necessário, o estudante poderá olhar rapidamente o esquema (cartaz, maquete), a fim de se lembrar de algum tópico ou da sequência da exposição.

\section{Ensaio}

Ensaiar a apresentação. Para isso o estudante deve ter à mão um gravador, celular (smartphone que faz os dois papeis de gravar e filmar) e o esquema. Com o gravador ligado, o estudante começa a exposição como se estivesse falando para a classe. Procurar falar com segurança e fluência, evitando consultar o roteiro (importante compreender o assunto a ser apresentado e não gravar/decorar o assunto). Quando o estudante terminar o ensaio é importante ouvir a gravação e avaliar o resultado. Se julgar necessário, ensaie outras vezes e, se possível, na presença de outras pessoas. $O$ ensaio na frente do espelho também contribui para a segurança. 


\section{Apresentação do seminário}

Durante a exposição podem ocorrer fatos não previstos. Por exemplo, o público pode não compreender bem o conteúdo da exposição, um aparelho audiovisual pode não funcionar, uma cartolina pode cair da parede; se o seminário for em grupo, um integrante do grupo pode faltar ou ficar nervoso e esquecer o texto, entre outras situações. Por isso, é preciso estar atento a vários aspectos simultaneamente $\mathrm{e}$, de acordo com a necessidade, introduzir modificações e improvisar soluções, a fim de alcançar o melhor resultado possível. Durante a exposição propriamente dita, deve-se evitar ler o que está escrito no roteiro, manter a postura com o peitoral aberto, voz alta e olhar para frente.

A seguir relaciona-se alguns aspectos que devem ser observados na apresentação de um seminário.

Sequência e andamento da exposição:

1. Abertura: o professor (ou um colega, o 'cerimonialista', previamente orientado para essa função) dá a palavra ao apresentador. Faz isso com palavras como "Vocês agora vão assistir ao seminário preparado por fulano, cujo tema é...".

2. Tomada da palavra e cumprimentos: o apresentador coloca-se à frente da plateia (ou turma), cumprimenta-a, apresenta-se e dá início ao seminário.

3. Apresentação do tema: o apresentador diz qual é o tema, fala da importância de abordá-lo e esclarece o ponto de vista a partir do qual irá abordá-lo. Se o tema for amplo, precisa ser delimitado, isto é, indica qual aspecto dele será enfocado. Por exemplo, se o tema é a 'poluição do meio ambiente' o apresentador pode delimitá-lo e tratar apenas da poluição dos rios. Esse momento do seminário tem em vista despertar na plateia curiosidade sobre o tema abordado. 
4. Exposição: o apresentador segue o roteiro traçado, expondo cada uma das partes, com clareza e sem atropelo. Ao final de cada uma, deve perguntar ao público se quer fazer alguma pergunta.

5. Conclusão e encerramento: o apresentador retoma os principais pontos abordados, fazendo uma síntese (resumo) deles; se quiser, pode mencionar aspectos do tema que merecem ser aprofundados em outro seminário; pode também deixar uma mensagem final, algo que traduza o seu pensamento ou o pensamento do grupo ou de um autor especial. No final, agradece a atenção do público e passa a palavra a outra pessoa (o 'cerimonialista' ou o professor).

6. Tempo: o apresentador deve estar atento ao tempo previsto e, de acordo com o andamento do seminário, ser capaz de introduzir ou eliminar exemplos e aspectos secundários, caso haja necessidade.

7. Enriquecendo o seminário com o uso de recursos audiovisuais: a principal linguagem de um seminário é a verbal. Contudo, o uso de recursos audiovisuais, como cartazes, slides, filmes, maquetes, modelos didáticos, entre outros, pode tornar o evento mais agradável ou facilitar a transmissão de um volume maior de informações. $O$ uso desses recursos exige, porém, certos cuidados:

- O equipamento deve ser testado previamente, para prevenir a ocorrência de falhas técnicas durante a exposição. Ver a bateria. Atentar para a possível falta de luz.

- O apresentador deve lembrar que tais recursos têm finalidade de servir de apoio à exposição oral e, portanto, não a substituem. Ao fazer uso de um cartaz, por exemplo, o estudante deve aproveitar para reunir ou esquematizar as informações que vem apresentando, em vez de simplesmente ler o que está escrito, aliás, não é para ler o cartaz e sim, para apresentar o cartaz à turma.

- A alternância da exposição oral com o uso de recursos audiovisuais geralmente dá leveza a um seminário, logo, alternar a fala com a apresentação do cartaz, modelo, maquete é um recurso estratégico 
interessante e dá tempo para o estudante ficar mais calmo e lembrar-se de algo, se necessário.

\section{O local do seminário}

Antes de iniciar o seminário, verificar se o local está adequado, considerando:

1. A arrumação da sala;

2. O tamanho da sala;

3. Água para beber, caso os estudantes sintam a boca seca;

4. A iluminação;

5. A ventilação;

6. A disposição das cadeiras (em fileira, em círculo);

7. Os recursos disponíveis;

8. A decoração (mesa, flores sobre a mesa, água, se for o caso).

9. Orienta-se a não colar o cartaz (isso prejudica a parede e o quadro posteriormente).

\section{Postura do apresentador.}

Posição: o apresentador deve, preferencialmente, falar em pé, com o esquema nas mãos, olhando para o público como um todo, peitoral aberto mostrando confiança. Não deve ficar com os braços e pernas cruzados. Deve evitar piscar, esfregar os olhos, mexer nos cabelos e gesticular excessivamente. Sugere permanecer sempre de frente para a plateia, mesmo quando usar o quadro, a maquete, o modelo, o cartaz; nessas situações, propõem-se ficar de lado e falar com a cabeça virada na direção do público, a fim de que sua voz seja ouvida por todos.

Voz, tom e ritmo: a fala do apresentador precisa ser alta, clara, bem articulada, com palavras bem pronunciadas e variações de entonação, de 
ritmo e de altura de voz, a fim de que a exposição não fique monótona e desinteressante. Ao falar o apresentador quer ser ouvido, portanto, o apresentador precisa treinar seu tom de voz para que a turma/plateia ouça.

Textos de apoio: ao consultar o roteiro, o apresentador deve fazê-lo de modo rápido e sutil, sem interromper o fluxo da fala. Se precisar ler uma citação, não necessita abaixar demasiadamente a cabeça, a fim de que a voz não se volte para o chão.

Relacionamento: o apresentador deve se mostrar simpático e receptivo a participações da plateia, mas estar atento para evitar polêmicas com uma única pessoa do público e se falar algo polêmico, estar preparado para o debate depois da apresentação. Ser simpático e cortês com o público; as críticas, que precisam ocorrer da parte do professor, são para o crescimento e para melhorar a próxima apresentação. Não é para interpretar como algo pessoal.

\section{Uso da linguagem}

Nos seminários, predomina a norma-padrão da língua, embora possa haver menor ou maior grau de formalismo, dependendo da intimidade entre os interlocutores. Assim:

- O apresentador necessita evitar certos hábitos da linguagem oral, como a repetição constante de expressões como: 'tipo', 'tipo assim', 'né?', 'ok', 'entendeu?', 'tendeu?', 'ahn', entre outras, pois elas prejudicam a fluência da exposição.

- Sempre que for necessário, o apresentador pode explicar o significado de vocábulo e conceitos específicos da área pesquisada; para isso, pode fazer usos de expressões de reformulação, como 'isto é', 'quer dizer', 'como', 'por exemplo', 'em outras palavras', 'vocês sabem o que é isso?'. Deve também fazer uso de expressões que confiram continuidade ao texto, como 'além disso', 'por outro lado', 'outro aspecto', 'apesar disso'. 


\section{Apresentação de um seminário em grupo}

A exposição em grupo exige atenção a alguns aspectos específicos:

Cada integrante do grupo pode ficar responsável pela apresentação de uma parte do seminário. Entretanto, o grupo todo precisa se "especializar" no assunto. Além de conferir maior segurança às exposições individuais, isso permite que todos respondam com tranquilidade a qualquer pergunta feita pelo público e se alguém faltar no dia, o grupo não seja prejudicado.

Entre a exposição de um participante e a de outro necessita haver coesão, isto é, não pode haver contradição entre as exposições nem ser dada a impressão de que uma fala é independente de outra, precisam seguir a ordem e a cadência do desenvolvimento do tema. Cada exposição deve retomar o que já foi desenvolvido e acrescentar, ampliar. Para garantir a coesão entre as partes, precisam ser empregados elementos linguísticos como: 'Além das causas que fulano comentou, vejamos agora outras coisas, menos conhecidas'; 'Vocês viram as consequências desse problema no meio urbano, agora, vão conhecer as consequências do mesmo problema no meio rural...'. Ou seja, de um participante para outro, para o próximo necessita haver continuidade do assunto.

Enquanto um dos apresentadores expõe, os outros ficam em pé, mas permanecem em silêncio, sem comunicação com a plateia, mesmo que com os olhares. Podem contribuir ajudando o colega que esqueceu uma palavra, segurando o modelo, trocando os cartazes, apagando o quadro ou simplesmente ouvindo com atenção a exposição, para ajudá-lo se necessário. Manter sempre a postura (peitoral aberto) e demonstrar confiança e respeito pelo colega que ainda está se expondo.

Atenção, porque precisam ser evitados, durante a realização de um seminário, comportamentos que desviem tanto a atenção do apresentador quanto a atenção do público, como conversas paralelas entre os membros do grupo ou entre um membro do grupo e uma pessoa da plateia, bem como movimentos, ruídos ou brincadeiras. Atenção especial à vestimenta, a 
maquiagem e acessórios, nada de exageros, quem deve aparecer é o apresentador e por seu conhecimento, não por sua vestimenta, entre outras. Afinal, o seminário é uma avaliação.

\section{Conclusão ou Considerações finais}

O assunto deve ser encerrado, todos os participantes precisam falar (se este foi o acordo com o docente), o material audiovisual precisa ser exposto e explicado para a turma/plateia. Ao terminar, alguém sinaliza para a turma/plateia que o seminário findou. Precisa levar as referências, ou seja, de onde retirou as informações, caso alguém questione.

\section{Compartilhando saberes}

Importante ter muito cuidado com o português, tanto o falado, quanto o escrito. Menos é mais, ou seja, quanto mais simples o cartaz, melhor: folha branca, com margem de régua, tema chamando a atenção, o cartaz deve ser lido a uma distância de cinco metros, logo, cuidado com a caneta usada, fonte usada e informações colocadas, sem rasuras. $O$ ideal é usar esquemas no cartaz, como figuras ou fluxogramas com palavras-chave. A margem não deve ser feita com papel crepom, necessário usar uma régua e ter limpeza e capricho no cartaz. No cartaz não existe "Trabalho de Ciências", "Trabalho de Biologia", e sim, o nome do tema, exemplo: "Célula procariótica"; "Briófitas"; "Mitose"; "Sistema Endócrino", entre outros.

A maquete, modelo didático, material didático, entre outros, pode ser preparada com material de baixo custo, pode buscar na internet modelos que venham a copiar ou estimular a criatividade para a confecção dos próprios modelos, mas tudo isso requer planejamento.

Orientar o estudante que se sente inseguro na apresentação a treinar o quanto antes. A partir do momento que o professor deu o tema do seminário o estudante já pode pesquisar e se preparar, seguindo as orientações dadas aqui e aquelas faladas por cada professor. Treinar na frente do espelho, gravar-se falando com som e imagem, vai dando segurança ao estudante. Quanto mais o estudante falar, mais seguro vai estar. Contudo, é importante avisar que trabalho de véspera não será bem 
avaliado. Oriente a antecipar-se e a estudar o tema, orientar sobre a gestão do tempo.

$\mathrm{Na}$ avaliação do seminário são pontos importantes que o professor precisa prestar atenção: clareza e coerência na apresentação; domínio da problemática (tema) na apresentação; participação do grupo observador (turma/plateia) durante a exposição e relação crítica da realidade. Além da autoavaliação de cada participante com justificativas. Considerando a série que está apresentando, o peso de um seminário apresentado pelo sexto ano do Ensino Fundamental não será a mesma avaliação e peso de um seminário apresentado por turmas da terceira série do Ensino Médio.

O professor também precisa participar de forma a incentivar a fala dos demais estudantes da turma e participar com comentários que venham a valorizar o trabalho do grupo e a incentivar a participação nos próximos seminários. O avaliador, que na maioria das vezes será(ão) o/os professor/professores precisa/ $\mathrm{m}$ ter o cuidado com os comentários, para não enaltecer um estudante em detrimento dos demais (para que um estudante não se sinta inferior frente aos outros colegas), e ao mesmo tempo em que for fazer um comentário desaprovando o que foi dito pelo estudante e endossado pelo grupo, deve-se orientar e elogiar. No final sempre parabenizar os estudantes, afinal, eles enfrentaram o desafio do seminário. Bater palmas é importante porque valoriza o trabalho do outro.

Um problema a ser indicado é a questão do tempo para todas as apresentações, o professor pode antecipadamente comunicar a orientação pedagógica que irá realizar um seminário em sua turma e que, portanto, irá extrapolar o tempo de aula. No Rio de Janeiro um tempo de aula ocorre em 50 minutos, mas normalmente as aulas são germinadas, ou seja, 100 minutos, mesmo assim pode inviabilizar as apresentações, porque há os debates e as autoavaliações depois, por isso ser um seminário com a participação de vários docentes, ou seja, com outros professores avaliando ser uma alternativa eficaz, mesmo que o tempo de aula de um professor termine, a apresentação continua com o outro docente que entrar na turma. Os professores precisam estabelecer parcerias para o trabalho fluir. Outra forma é dividir as apresentações em vários dias. 
Aqui foram apresentadas orientações de uma professora que trabalha a mais de dez anos com o sexto ano e que utiliza o seminário como estratégia didática para o ensino e aprendizagem. Pode e precisa haver outros olhares, comentários, censuras, desaprovação e críticas a respeito do aqui apresentado. $O$ importante é que o docente compreenda a importância do seminário e de seu papel na apresentação. Contextualizações, ressignificações e novas reflexões são importantes para o aprimoramento desta técnica de ensino em cada contexto escolar que cada docente é qualificado para fazer.

\section{A discussão}

Por meio dos seminários os professores podem subverter o sistema dominante e dar aos estudantes outros olhares. Os seminários vêm de forma ambígua, pois no sexto ano, os professores, provavelmente, selecionarão os temas, e estes podem ser tradicionais e que reproduzem o sistema social e econômico (florestas para o uso dos humanos, por exemplo), ou, 'transgressor', como a Educação Ambiental Crítica, que desaprova categoricamente o sistema capitalista opressor (LEFF, 2015).

A apresentação do seminário como prática pedagógica a partir do sexto ano dos anos finais do Ensino Fundamental é possível de acontecer. Para tanto, foram apresentados na seção anterior, a preposição, importantes aspectos que devem ser orientados pelo docente. Com a realização de tais orientações e outras que venham a surgir a partir do momento que a prática for realizada em cada contexto escolar, é possível que o seminário se torne uma rotina para o estudante e esse cada vez mais venha a se empenhar em sua realização.

Com isso o seminário alcança sua razão de existir: contribuir para o desenvolvimento cognitivo e social do educando, cidadão e futuro trabalhador (RONCATO; LACERDA, 2005; VIEIRA; VIERA, 2005; CANELLI, 2011; MONTEZI; SOUZA, 2013; BOURDIEU; PASSERON, 2014; MATURANA, 2014; TARDIF; LESSARD, 2014; LEAL, 2017; LEAL; MIRANDA; NOVA, 2018). 
Na educação pública o seminário mostra-se uma avaliação de baixo custo e que pode ter abordagens interdisciplinares enriquecendo, portanto, o conhecimento do estudante, da turma e promovendo esta prática na escola. Torna-se salutar e profícuo para o próprio indivíduo que levará esta prática pedagógica para as demais séries escolares, seu ambiente secular e para si. E contribui para as interações docentes por meio das trocas de saberes (TARDIF, 2014).

\section{Considerações finais}

Por meio da prática pedagógica proposta abre-se espaço para os estudantes assumirem um papel protagonista e alcançar o desenvolvimento cognitivo e social. É uma estratégia didática indiscriminatória, cooperativa, e que abarca todas as disciplinas escolares. Também é uma técnica progressiva porque a cada nova apresentação o indivíduo estará mais bem preparado, menos nervoso, menos ansioso, mais criativo, mais audacioso, por exemplo.

O docente precisa sempre estar atento quando for indicar o exercício do seminário para turmas do sexto ano, atento aos estudantes, pois nem toda pressão provoca a mesma reação; há estudantes que não se adaptam ao seminário, de forma que a escola precisa ofertar diversas estratégias didáticas para tentar abarcar a todos, a mais tradicional é a prova. É em vão ameaçar com perda de ponto se o estudante revelar que não irá apresentar, mas deve-se providenciar outra avaliação para o estudante e não pressionálo e acabar abalando sua autoestima. Pode-se dar um tempo para que ele observe que não é tão difícil assim. A escola precisa ser um ambiente formativo e não excludente e muito menos traumatizante.

Os professores do sexto ano, e outros, podem promover o seminário com banca de avaliadores, ou seja, com outros professores participando, a fim de ser uma avaliação bimestral final, isto resolveria a questão do tempo das apresentações, pois seria um dia separado para esta atividade. No seminário os professores também aprendem por meio dos saberes docentes de outro e por meio das experiências visualizadas, além da própria prática pedagógica. Para isso, torna-se necessário no planejamento escolar inserir o 
seminário como algo que pode ser vivenciando e praticado desde os primeiros momentos em sala de aula, para que quando for apresentar para os professores ou a banca, os estudantes já estejam mais habituados com a estratégia.

Para o professor, independentemente da etapa educacional em que atua, o seminário é importante, pois pode-se abordá-lo com outras disciplinas, exemplo: Ciências, Geografia e Língua Portuguesa, então, uma atividade pode servir como instrumento avaliativo em outras disciplinas. $O$ que poupa tempo nas avaliações, além de ser uma avaliação pontual, ou seja, a nota do estudante já é dada naquele momento, sem necessitar levar para correções posteriores.

Ao professor do sexto ano, alerta-se para que o mesmo lembre-se da afetividade, não castre a afetividade dos estudantes, nem os constranja com a demonstração de carinho comum nesta série, mas que os ajudem a atravessar este percurso do início dos anos finais do Ensino Fundamental, sabendo que eles têm um ambiente acolhedor e pessoas afáveis e receptivas as suas demandas.

Vê-se a importância de utilizar o seminário a partir do sexto ano dos anos finais do Ensino Fundamental como recurso nas estratégias de ensino e aprendizagem em todas as disciplinas e de forma disciplinar ou mesmo interdisciplinar. Do ponto de vista psicológico do estudante desta série, é necessário acompanhar e analisar a prática pedagógica, seja ela realizada de forma individual ou em grupo, focando nas relações e nos processos de ensino e aprendizagem, o professor precisa assumir um papel de 'parceiro cooperativo ativo' e uma fonte para a qual o estudante pode procurar em caso de dúvidas, problemas, entre outras questões. O papel do professor também muda no uso do seminário, ele necessita estar ciente de que será uma referência para seus estudantes, precisa ser proativo e uma liderança.

Para iniciar o seminário no sexto ano, sugere-se um exercício individual de apresentação de biografias, ou seja, cada estudante ficará responsável por apresentar a biografia de um cientista, de uma pessoa famosa, de um acadêmico. Além de apresentar a biografia desenvolver 
também um acessório audiovisual, como uma maquete, um quadro, uma linha do tempo e assim ir treinando para um seminário maior, em grupo e com o tema escolhido pelo professor. É apenas uma sugestão para o primeiro passo, já que os estudantes vão desenvolvendo confiança em si mesmo.

Portanto, por meio da preposição apresentada neste estudo, percebe-se ser possível a apresentação do seminário e que este alinhado a outras metodologias ativas de ensino e aprendizagem colaboram para o desenvolvimento cognitivo e pessoal do estudante, e mais, liberta-o da atribuição 'empregado-empregador', tão afirmativa no campo da sociologia da educação. Ao menos, terá consciência de classe por conta dos amadurecimentos que o estudante terá ao longo da educação básica por meio de pesquisas e debates. Seminário é uma outra maneira de ensinar e os estudantes aprenderem, há outras.

A respeito da educação pública, o seminário mostra-se bastante profícuo de experiências porque demanda a pesquisa e o estudante passa a exercer sua cidadania plena de conhecimentos e respeitando os demais indivíduos sociais, assim como a proatividade. O exercício do seminário permite a compreensão de outras áreas além das disciplinas envolvidas e a auto realização, a alegria, o orgulho de si e promove autoconfiança do indivíduo.

Termina-se este estudo resgatando a origem latina do termo seminário, que seja uma técnica de ensino que de fato semeie conhecimento, e que o polinize e brote em outros estudantes e participantes do seminário, sendo professores ou outros colegas. Todos são capazes de aprender, compreender e ensinar e, o seminário permite desenvolver inúmeras competências e habilidades necessárias para os cidadãos de fato exercerem sua cidadania, por meio do compartilhamento de saberes. 


\section{Referências}

ARAÚJO, M. F.F.; PRAXEDES, G. C. A aula passeio da pedagogia de Célestin Freinet como possibilidade de espaço não formal de educação. Ensino em Revista, v. 20, n. 01, 2013.

BOURDIEU, P.; PASSERON, J. C. A reprodução: elementos para uma teoria do sistema de ensino. Tradução: Reynaldo Bairão. $7^{a}$ ed. Petrópolis: Vozes, 2014. 275p.

CAINELLI, M. R. Entre continuidades e rupturas: uma investigação sobre o ensino e aprendizagem da História na transição do quinto para o sexto ano do Ensino Fundamental. Educar em Revista, v. 27, n. 42, p. 127-139, 2011. https://doi.org/10.1590/S0104-40602011000500009.

LEFF, E. Saber ambiental: sustentabilidade, racionalidade,

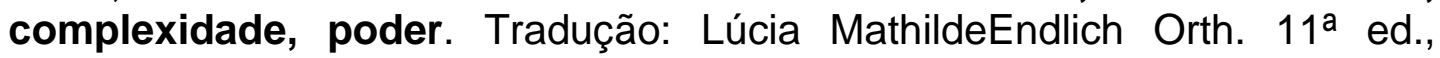
Petrópolis: Vozes, 2015. 494p.

LEAL, C. A. Estratégias didáticas como proposta ao ensino da genética e de seus conteúdos estruturantes. 2017. 305f. Tese. Programa de PósGraduação Stricto sensu em Ensino em Biociências e Saúde (PG-EBS), Instituto Oswaldo Cruz, Fundação Oswaldo Cruz (IOC/Fiocruz). Campus Manguinhos. Orientadora: Prof. ${ }^{\text {a }}$ Dra. Rosane Moreira Silva de Meirelles. Rio de Janeiro, 2017.

LEAL, E. A.; MIRANDA, G. J.; NOVA, S. P. C. C. Revolucionando a sala de aula: como envolver 0 estudante aplicando as técnicas de metodologias ativas de aprendizagem. 1를 ed. São Paulo: Atlas, 2018. $235 p$.

MATURANA, H. R.; VARELA, F. J. A árvore do conhecimento: as bases biológicas da compreensão humana. Tradução: Humberto Mariotti e Lia Diskin. 9ª ed. São Paulo: Palas Athena, 2011. 283p.

MATURANA, H. R. Cognição, ciência e vida cotidiana. Tradução: Cristina Magro e Victor Paredes. 2ª . ed. Belo Horizonte: Editora UFMG, 2014. 219p.

MEIRA, G. H. F.; S., W. M. Seminário acadêmico, mais que um gênero: um evento comunicativo. Anais... SILEL. v. 03, n. 01. Uberlândia: EDUFU, 0114p, 2013.

MONTEZI, A. V.; SOUZA, V. L. T. Era uma vez um sexto ano: estudando imaginação adolescente no contexto escolar. Psicologia Escolar e Educacional, v. 17, n. 01, p. 77-85, 2013.

MORA, F. Neuroeducación: solo se puede aprender aquello que se ama. 2ee․ Madrid: Alianza editorial, 2017. 245p.

RONCATO, C. C.; LACERDA, C. B. F. Possibilidade de desenvolvimento de linguagem no espaço da Educação Infantil. Distúrbio da Comunicação, v. 02, n. 17, p. 215-223, 2005. 
TARDIF, M. Saberes docentes e formação profissional. Tradução: Francisco Pereira. $17^{a}$ ed. Petrópolis: Vozes, 2014. 325p.

TARDIF, M.; LESSARD, C. $\mathbf{O}$ trabalho docente: elementos para uma teoria da docência como profissão de interações humanas. Tradução: João Batista Kreuch. $9^{\mathrm{a}}$ ed. Petrópolis: Vozes, 2014. 317p.

VIEIRA, R. M.; VIEIRA, C. Estratégias de ensino/aprendizagem. Coleção: Horizontes Pedagógicos, $1^{\underline{a}}$ ed.: Lisboa: Instituto Pedagógicos, 2005. 152p. 